\title{
Identification and characterization of phytoplasma associated with brinjal little leaf, phyllody and witches' broom disease in India
}

\author{
MEGHA MAHESHWARI, MANISH KUMAR*, MADHUPRIYA and G.P. RAO \\ Plant Virology Unit, Division of Plant Pathology, ICAR-Indian Agricultural Research Institute, New Delhi 110012 , India
}

Received: 1 March 2017/ Accepted: 27 May 2017/ Published online: 31 May 2017

OIndian Phytopathological Society 2017

\begin{abstract}
Symptoms of little leaf, phyllody and witches' broom on brinjal plants were recorded at New Delhi, Uttar Pradesh, Maharashtra and Chhattisgarh states of India in 2016. The disease incidence was recorded in the range $5-20 \%$ in different surveyed fields. PCR assays were performed using universal primers specific to the phytoplasma 16S rRNA gene: P1/P7 followed by 3F/3R which yielded $1.3 \mathrm{~kb}$ amplified products in nested PCR assays in eight symptomatic plants from all the four surveyed states but not from any healthy controls. Pair wise 16S rDNA sequence comparison and phylogenetic analysis of BLL isolates revealed their close relationship with strains of 'Candidatus Phytoplasma trifolii' (16SrVI group). In silico RFLP analysis through pDraw32 program further confirmed subgrouping of the phytoplasma strains associated with brinjal little leaf and witches' broom disease in 16SrVI-D subgroup.
\end{abstract}

Keywords: BLAST, brinjal, In silico RFLP, PCR assay, Phytoplasma

Phytoplasmas are wall-less prokaryotes that parasitize plants and insects and constitute a large monophyletic group within the class mollicutes. Phytoplasmas are obligate intracellular parasites that reside in the sieve cells of plant phloem tissue and cause diseases in hundreds of plant species worldwide (Bartacinni et al., 2014). The trivial name phytoplasma is now given designation status of Candidatus phytoplasma (Bartacinni et al., 2014). The 16S rDNA sequences had determined and used in the late 1990s for classification of phytoplasma into 33 phylogenic groups (Zhao and Davis, 2016). BLL is a very serious disease causing severe losses to brinjal crops and is widespread in brinjalgrowing regions of India. Phytoplasma etiology of BLL disease in India has been confirmed on the basis of symptoms, electron microscopy, DAPI staining and PCR assays (Das and Mitra, 2004; Kumar et al., 2017; Rao and Kumar, 2017).

Survey of brinjal fields in four states viz. Delhi, Uttar Pradesh, Maharashtra and Chhattisgarh, India, during January-June 2016 shown 5-20\% disease incidence and exhibited phytoplasma suspected symptoms of little leaf, stunting, shortened internodes, the proliferation of shoots and phyllody asymptomatic (Fig. 1). The symptomatic and healthy samples were collected and analyzed for phytoplasma etiology. The nucleic acid was extracted (Ahrens and Seemuller, 1992) from mid rib portion of leaves of symptomatic and non-symptomatic brinjal plants and amplification of phytoplasma ribosomal DNA

${ }^{*}$ Corresponding author: sharma90manish@gmail.com
(rDNA) was performed with the universal phytoplasma nested primer pairs P1/P7 and 3F/3R as followed by Manimekalai et al. (2010). The DNA isolated from periwinkle infected with toria phyllody phytoplasma (group 16SrIX, pigeon pea witches' broom phytoplasma) maintained in the greenhouse was used as a positive control.

The DNA extracted from asymptomatic brinjal leaves was used as negative control. Reactions were carried out in a Mastercycler (Eppendorf) and the cycling protocol given by Sumi et al. (2015) was used for the first round PCR. Two $\mu$ l product of the first round PCR was used in nested PCR assays using internal primer pair 3F/3R. Cycling protocol described by Manimekalai et al. (2010) was used for nested PCR assays. Five microlitres of each PCR product was subjected to electrophoresis using $1.0 \%(\mathrm{w} / \mathrm{v})$ agarose gel stained with ethidium bromide and observed under UV transilluminator. Nested PCR product (1.3 kb amplicon) was purified using the WizardR SV Gel and PCR Cleanup System (Promega) and amplified products were sequenced directly in both directions using the nested PCR primers. The sequences were aligned using CLUSTAL W method of Bio-Edit software (Bio-edit Sequence Align Editor) and the consensus sequence was submitted to GenBank and used in BLAST search. The test sequence and reference phytoplasma strains sequences retrieved from GenBank were used to derive phylogeny through MEGA 6.0 software (Tamura et al., 2013). The BLL phytoplasma sequences corresponding to the $3 F / 3 R$ region were subjected to in silico RFLP 


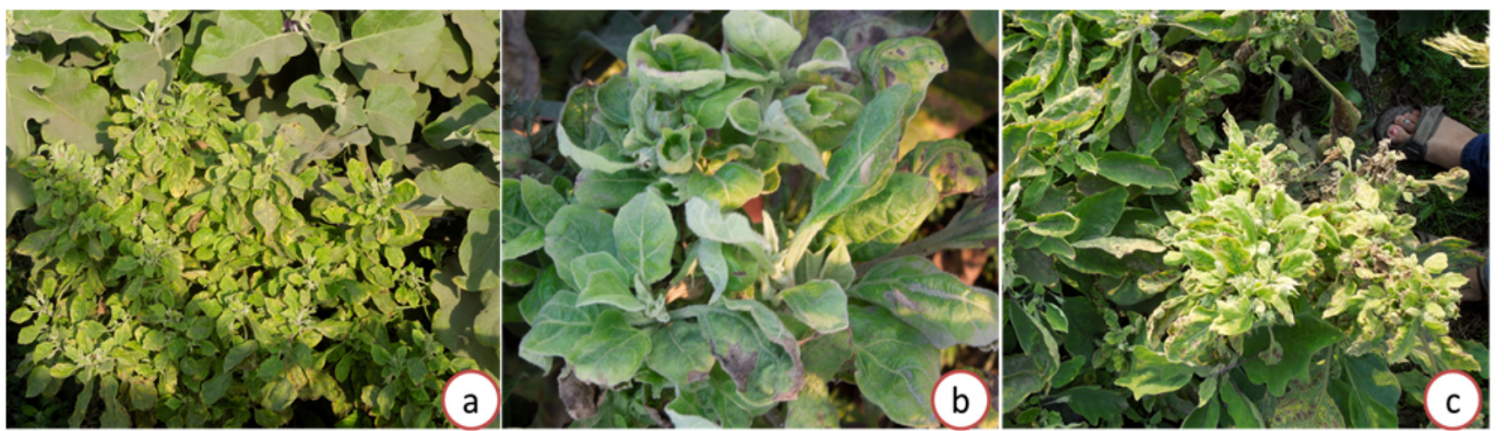

Fig. 1. Phytoplasma suspected symptoms in brinjal plants; (a) Little leaf symptoms in DBHL-20 isolate from IARI; (b) Phyllody symptoms at NBPGR; (c) Typical witches' broom symptoms caused by Varanasi isolate from Uttar Pradesh

analysis using pDRAW32 program developed by AcaClone Software (http://www.acaclone.com).

PCR amplification did not yield expected $1.8 \mathrm{~kb}$ product of the $16 \mathrm{~S}$ rDNA region from any symptomatic brinjal plants with primer pair P1/P7, except with positive control of toria phyllody phytoplasma infected leaf samples (data not shown). However, $1.3 \mathrm{~kb}$ amplicon in nested PCR products were observed with $3 F / 3 R$ primers in all symptomatic brinjal DNA samples and the positive control of toria phyllody phytoplasma infected Catharanthus roseus leaf tissue. No DNA was amplified by nested PCR assay from the template DNA isolated from any of the non-symptomatic healthy samples. The partial 16S rRNA gene sequences of eight BLL isolates were deposited in GenBank database (Table 1). BLAST analysis of $16 S$ rRNA gene partial sequences of BLL strains showed sequence identity of $99 \%$ with phytoplasma strains of periwinkle little leaf (AF228053), Saponaria stunting and witches' broom phytoplasma (KX641021), sesame phyllody phytoplasma (JF508514) and brinjal little leaf phytoplasma (KX284698; AF228052) belonging to clover proliferation group (16SrVI).

In the phylogenetic analysis, $16 S$ rRNA gene partial sequence of brinjal little leaf phytoplasma strains in the present study clustered together with strains belonging to $16 \mathrm{SrVI}$ group (Fig. 2). The virtual RFLP analysis of the $3 F / 3 R$ region using pDraw online tool (http:// www.acaclone.com) with 17 selected restriction enzymes for the representative BLL phytoplasma strains was performed for $16 \mathrm{~S}$ subgroup assignments. Virtual RFLP analysis results revealed that BLL phytoplasma Delhi strain (KX421254, KX421255, KX421256), Uttar Pradesh strain (KX421257, KX421260, KX421261), Maharashtra strain (KX421253) and Chhattisgarh strain (KX421259) produced RFLP profiles identical to those of phytoplasma reference strain of $16 \mathrm{SrVI}-\mathrm{D}$ subgroup (Ac. No. AF2280894) (Fig. 3). Earlier, the natural occurrence of different groups of phytoplasma on brinjal has been reported from different parts of the world (Rao and Kumar, 2017). So far, phytoplasmas belonging to six groups, viz. 16Srl from Japan, Bangladesh and India, 16Srll-D from Egypt, 16SrllI-J and 16SrllI-U from Brazil, 16SrVI-D from India, 16SrIX-C from Iran and 16SrXII-A from Russia were reported to infect brinjal worldwide (Rao and Kumar, 2017). In the present study, association of $16 \mathrm{SrVI}-\mathrm{D}$ subgroup was confirmed with BLL strains infecting brinjal plants in four states of India on the basis of sequence comparison, phylogeny and RFLP analysis of $16 \mathrm{~S}$ rDNA sequences. Kumar et al. (2017) identified

Table 1. Distribution and incidence of brinjal little leaf disease in four states of India along with GenBank submission and phytoplasma identification in brinjal

\begin{tabular}{|c|c|c|c|}
\hline State/Place & $\begin{array}{c}{ }^{*} \text { Average } \\
\text { Incidence (\%) }\end{array}$ & $\begin{array}{c}\text { GenBank } 16 S \text { rDNA sequences for } \\
\text { BLL phytoplasma strains }\end{array}$ & $\begin{array}{l}\text { Group/subgroup } \\
\text { Identified }\end{array}$ \\
\hline \multicolumn{4}{|l|}{ Delhi } \\
\hline IARI 1 isolate & $6-13$ & KX421256 & 16SrVI-D \\
\hline IARI 2 isolate & $6-10$ & KX421254 & 16SrVI-D \\
\hline NBPGR isolate & $7-10$ & KX421255 & 16SrVI-D \\
\hline \multicolumn{4}{|l|}{ Uttar Pradesh } \\
\hline Etah (Nadrai) isolate & $4-11$ & KX421257 & 16SrVI-D \\
\hline Varanasi 1 isolate & $5-10$ & KX421260 & 16SrVI-D \\
\hline Varanasi 2 isolates & $5-10$ & KX421261 & 16SrVI-D \\
\hline \multicolumn{4}{|l|}{ Chhattisgarh } \\
\hline Raipur isolate & $2-10$ & KX421259 & 16SrVI-D \\
\hline \multicolumn{4}{|l|}{ Maharashtra } \\
\hline Baramati isolate & $5-14$ & KX421253 & 16SrVI-D \\
\hline
\end{tabular}

${ }^{*}=$ Average incidence of four plots was calculated for each location 


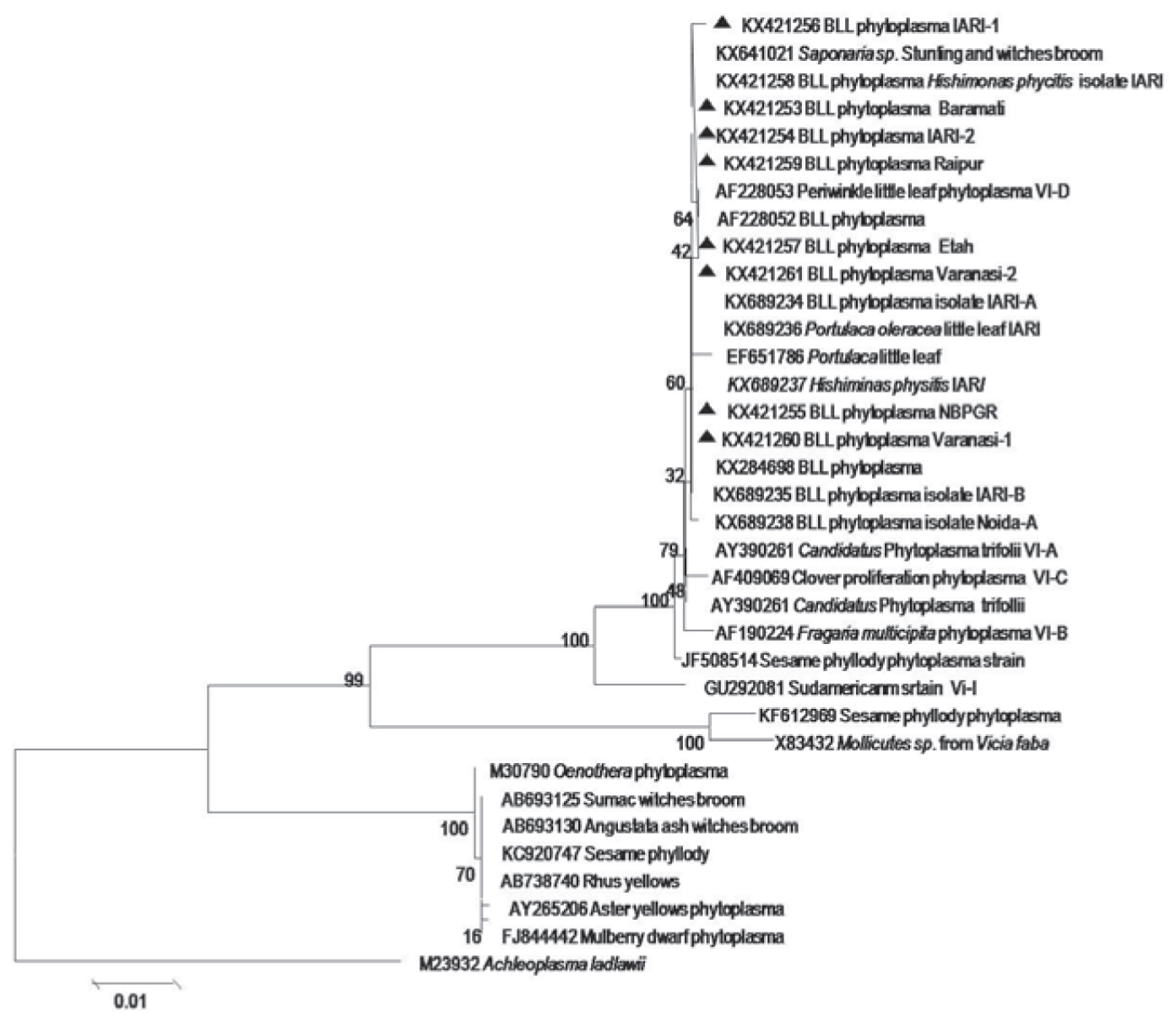

Fig. 2. Phylogenetic relationship between the BLL phytoplasma - India isolates and reference phytoplasma strains based on Mega6.0 software. Accession numbers are specified in the tree

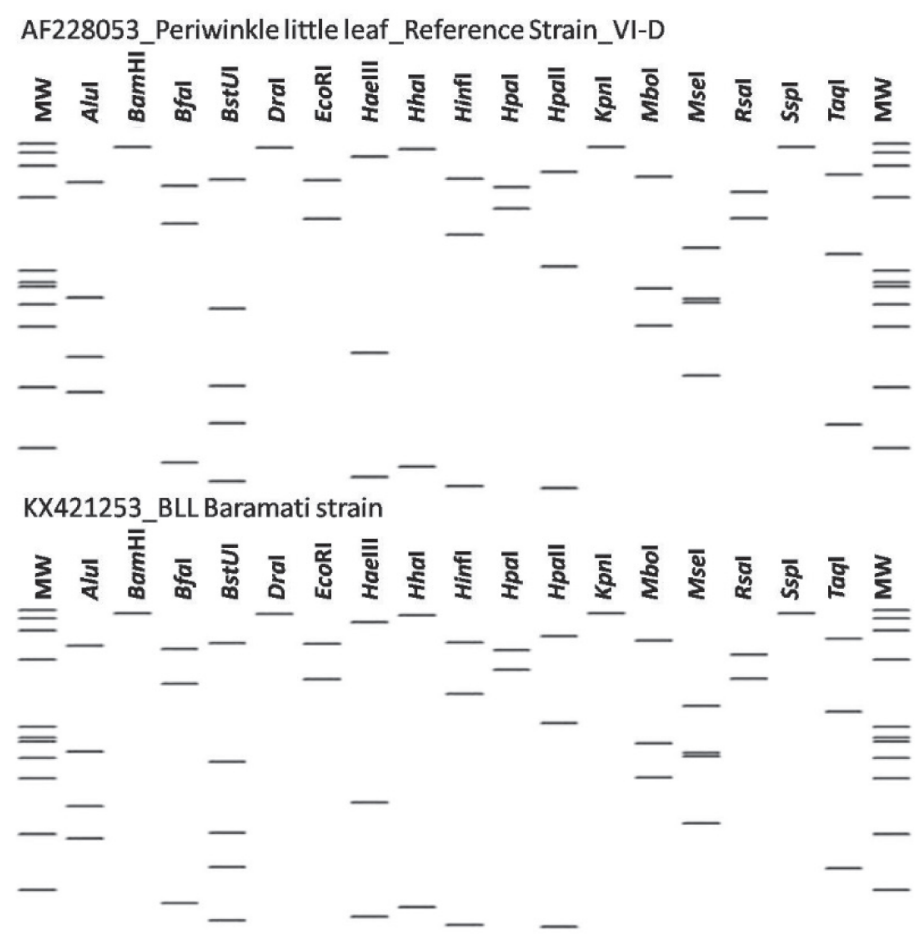

Fig. 3. Virtual RFLP patterns from in silico digestions of 16S rDNA 3F/3R fragments of: (a) AF228053, Reference Strain 16SrVI-D (AF228053), (b) KX421253, BLL Baramati strain. Restriction patterns of same phytoplasma strains representing 16SrVI-D subgroups are shown. Recognition sites for the following 17 restriction enzymes were used in the simulated digestions: Alul, BamHI, Bfal, BstUl (Thal), Dral, EcoRl, Haell, Hhal, Hinfl, Hpal, Hpall, Kpnl, Mbol (Sau3A), Msel, Rsal, Sspl, and Taql. MW: I kb DNA ladder 
the association of two major groups of phytoplasma with brinjal little leaf disease in eight states of India and also confirmed wider spread of BLL phytoplasma 16SrVI-D strains. Our results also confirmed that 16SrVI-D phytoplasma is the most widespread strain infecting brinjal crops in India. Hence, immediate attention is required to identify the other important epidemiological sources for the natural spread of brinjal associated phytoplasmas in India, which is little attempted so far in the country.

\section{ACKNOWLEDGEMENTS}

Authors are thankful to ICAR Extramural research fund provided by ICAR, New Delhi, India.

\section{REFERENCES}

Ahrens U and Seemuller E (1992). Detection of DNA of plant pathogenic mycoplasma like organisms by a polymerase chain reaction that amplifies a sequence of the 16S rRNA gene. Phytopathology 82: 828-832.

Das AK and Mitra DK (2004). Detection of brinjal little leaf phytoplasma in situ by light and fluorescence microscopy. Indian Phytopath. 57: 242-244.
Bertaccini A, Duduk B, Pattrinieri S and Contaldo N (2014). Phytoplasmas and phytoplasma diseases: A severe threat to agriculture. Amer. Jour. PI. Science 5: 1763-1788.

Kumar M, Priya M and Rao GP (2017). Molecular characterization, vector identification and sources of phytoplasmas associated with brinjal little leaf disease in India. 3 Biotech 7: 1-11.

Manimekalai R, Soumya VP, Sathish Kumar R, Selvarajan R, Reddy K, Thomas GV, Sasikala M, Rajeev G and Baranwal VK (2010). Molecular detection of $16 \mathrm{SrXI}$ group phytoplasma associated with root (wilt) disease of coconut (Cocos nucifera) in India. Plant Dis. 94: 636-636.

Rao GP and Kumar M (2017). World status of phytoplasma diseases associated with eggplant. Crop Prot. 96: 22-29.

Sumi K, Madhupriya, Manimekalai R, Rao GP and Rao KRS (2015). Identification and genetic relationships of phytoplasma strains infecting coconut, arecanut and oil palm in South India. Indian Phytopath. 68: 207-214.

Tamura K, Stecher G, Peterson D, Filipski A and Kumar S (2013). MEGA6: Molecular evolutionary genetics analysis version 6.0. Mol. Biol. Evol. 30: 2725.

Zhao $Y$ and Davis RE (2016). Criteria for phytoplasma $16 \mathrm{Sr}$ group/subgroup delineation and the need of a platform for proper registration of new groups and subgroups. Int. J. Syst. Evol. Microbiol. 66: 2121-2123. 